\title{
Modelling of Effects of Rockbursts on Steel Arch Roadway Support Underground
}

\author{
Petr Horyl VŠB-Technical University of Ostrava, Czech Republic \\ Richard Šnupárek Institute of Geonics Academy of Sciences of the Czech Republic
}

\begin{abstract}
During wind-up period of underground mining activities in Ostrava-Karviná coalfield (hereafter OKC) the rock bursts in course of coal winning have represented a considerable problem. At present rock bursts with focuses in more distant surroundings of affected mine workings are prevailing. Maximum effects of rock bursts occur above all in gateways and this impact is connected with lower load-bearing capacity of roadway support when compared with longwall face support. A research of behaviour of steel arch roadway support at dynamic load based on mathematical modelling is being carried out for determining effective methods of reinforcing of roadway support. Steel support by sets is being modelled by means of shell elements in programming file ANSYS, dynamic load from roadway side has been characterized by initial speed or eventually by impulse of force. The outputs of modelling were as follows: shape and nature of permanent strain of support, critical quantity of energy causing permanent strain of support, degree of total plastic strain (deformation) as well as impact of interaction of adjacent environment on the above-mentioned characteristics.
\end{abstract}

\section{INTRODUCTION}

Mining of hard coal in OKC which is part of Upper Silesian hard coal basin has been especially during the last decades accompanied by underground rockburst events. The increase of number of rockbursts and of their energy level has dated since seventies of twentieth century and it is connected with advance of coal production (above all in Karviná part of $\mathrm{OKC}$ ) into a domain of very thick seams (exceeding $2.5 \mathrm{~m}$ thickness) with between coal seams strata formed by layers of rigid sandstones, siltstones and conglomerates (Lower Suchá seams and Saddle seams - Upper Carboniferous: Middle and Upper Namurian). Unfavourable impacts of rockbursts on domain of safety and hygiene of miners and naturally also on costs sphere and on total economy of coal production have led to necessity to investigate in a more detailed manner the conditions of genesis and action of such dynamic events and to adopt effective measures both for technological and legislative spheres.

\section{STATE OF THE ART}

In the course of the last fifteen years conditions of underground coal mining in OKC changed conspicuously in connection with privatisation and restructuring of coal mining companies. Winding-up of mining activities and reducing of coal production led to closure of all underground coal mines in Ostrava part of OKC. Centre of gravity of coal production moved to Karviná part of OKC and thus also the share (and equally the quantity) of coal output from coal seams endangered by rock bursts increased. This reality has caused that even at a reduction of total coal output the rockbursts are still occurring. The development of characteristic indices during the last 25 years is represented in Fig. 1 Konečný et al. (2003).

Geological structure of Carboniferous rockmass is variable as it should be in a typical multi-seam deposit. Vertical distance between seams varies from several meters up to tens of meters. The positions between coal seams are formed predominantly by rigid bench-like sandstones and siltstones of uni-axial strength of 70-90 MPa. Coal strength amounts to

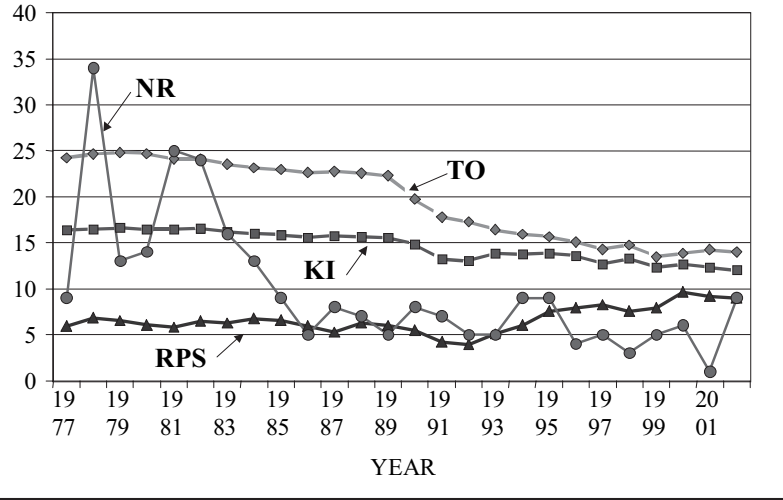

FIG. 1 Development of coal output of OKC in million $t / a$ structured into total coal output (TO), output of Karviná part of coalfield (KI), output of rockburst prone seams (RPS) compared with number of rockbursts (NR)

about 20-25 MPa. Currently the mining depth varies within depth range of $800-900 \mathrm{~m}$. Mean thickness of extracted seam exceeds conspicuously $2 \mathrm{~m}$.

The analysis of genesis and effects of rockbursts based on performed measurements resulted into defining of two basic types of underground rockbursts. During initial historical phase (seventies and eighties of the last century) so called in-seam rockbursts prevailed with focuses in close vicinity of mine workings. They were manifested by brittle failure of coal seam with minimum disturbance of adjacent roof and floor rock strata (so called shelf effect). At present time when coal winning has advanced below a $150 \mathrm{~cm}$ thick layer of rigid rock strata within roof of coal seam $\mathrm{N}^{\circ} 37$ the rockbursts of the other type, i.e with focus in a more distant - as a rule overlying environment - are prevailing. The mechanism of such rockburst is that at a sudden failure of a structure unit of rockmass (usually of a rigid layer between coal seams) a seismic event arises and seismic waves propagating in rockmass are provoked. The stress in wave front superimposes the stresses in rockmass. A release of elastic deformation energy in the vicinity of mine workings can cause a rockburst with all its 
consequences within a distance of tens up to hundred meters from initiation focus. The prediction and prevention of such rockbursts are ever more complicated and difficult.

This structuring has a considerable practical importance in view of selection of optimum measures of preventing or at least reducing of rockbursts effects. While in case of rockbursts with focuses in close vicinity of mine workings the measures are concentrated at elimination or reduction of unfavourable stress conditions in near proximity of mine working, in case of rockbursts with remote focuses the attention has to be paid to passive measures for protecting and safeguarding of roadways in which there is potential danger of rockburst.

The analysis of manifestations of underground rockbursts has indicated a principal difference between the effects of rockbursts on gates of longwalls and the effects on maintained longwall face areas. The effects on gateways are distinctly more intense than they are on secured longwall face area even if they occur at lower energy level of dynamic events. For instance out of 34 analysed rockbursts 22 had effects only on gateways and they had not any effect on longwall face area. It can be deduced that for occurrence of underground rockbursts (in view of damaging of mine working) the resistance of support is decisive. By high load-bearing capacity of longwall confining powered support, by its preloading and by its contact with rockmass equally their resistance against high-energy seismic events is more safeguarded, although in roadways with support of substantially lower loadbearing capacity also weaker energy events are manifested. An example of roadway support condition after a rockburst is represented in Fig. 2.

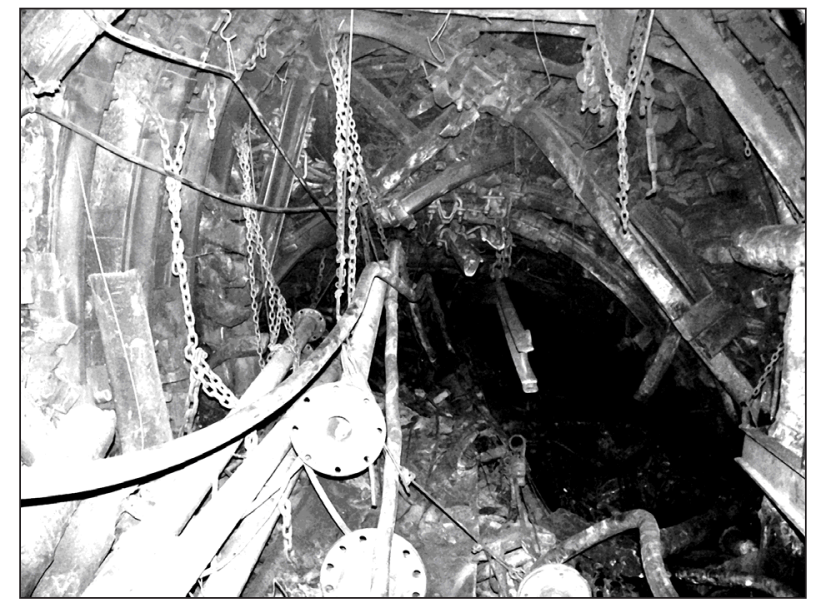

FIG. 2 Gateroad after rockburst

The roadways are supported in an absolute majority of cases by arch shaped steel sets of TH support, which is not preloaded and its contact with adjacent rock is not sufficient. Mostly open structures are concerned with relatively low resistance against load from roadway side and from roadway floor (such load is most frequent in case of rock bursts). Another weak point in view of dynamic load is longitudinal interconnection of individual support sets (quality and properties of sprags). The proper reinforcing measures therefore must include a reinforcing of structure of steel support of roadways both in regard to load-bearing capacity of individual sets and to load-bearing capacity of total support system. Another domain at which the attention is to be concentrated, is influencing of physico-mechanical characteristics of rocks and coal in roadway surroundings (reinforcement, enhancing of deformability). By the measures a brittle failure of rocks is reduced. This will reduce the dynamic impact on proper roadway support and backfilling of roadway by failed rock and coal. Among the well-developed and applicable procedures belong reinforcing grouting and anchoring of adjacent rockmass.

The effective adaptations of steel support of underground roadways in areas with rockburst danger had to be based on knowledge of behaviour of support at the most frequent ways of dynamic load acting on it.

\section{COMPUTER MODELLING}

The aim of computer modelling is detection of behaviour of steel support during the course of dynamic response provoked by rockburst. It deals primarily with the following:

- Shape and nature of permanent strain or deformation of steel support.

- Critical amount of energy by which a permanent strain is caused.

- Degree of total plastic strain.

- Effect of interaction of adjacent environment on the above-mentioned characteristics.

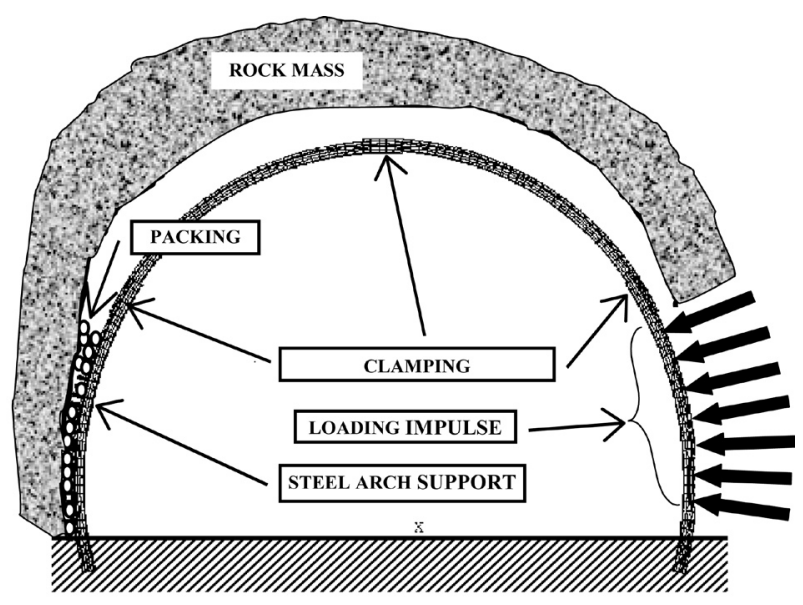

FIG. 3 Scheme of steel arch support

From the point of view of computer models the problem to be solved represents a number of uncertainties in view of mechanics. Especially the uncertainty of boundary and initial conditions are concerned. as it is evident from real situation of support in underground roadway, see Fig. 3. There are uncertainties in regard to bedding of base parts of roadway support on roadway floor, to real height of packing of support interacting during dynamic process, to magnitude and nature of load (change of initial conditions or realisation of impulse of force) etc. It is necessary to verify these "uncertainties" by means of parametric computations and to adopt real prerequisites, at which further computer simulations shall be proceeded. The instrument of computer modelling is a finite element method - FEM) which is applied by ANSYS program. Theoretically it is possible to create FEM models of roadway support of beam elements, of shell elements or of solid volume elements. By means of beam elements it is not possible to detect a permanent strain of support which is featured by warping of proper profil of beam, for instance by opening of "V" profile, see Horyl and Hlaváčková (1999). The solid volume elements bring then considerable problems with big number of degrees of freedom of numerical models. As an optimum solution the application of shell type elements appears by which, however, bending is transferred. Due to work with permanent (plastic) strain it is necessary to adopt a bilinear material properties of steel in such a way as this possibility is offered by the ANSYS program, see Fig. 4. One of the primary aims of computer solution was to 
determine the value of initial conditions so that they could act a marked plastic strain of roadway support. Theoretically we are able to provoke a movement of structure by introducing initial speed or deviation or to realize an impulse of force. With a rockburst it seemed real to introduce initial speed caused by throwing out of coal substance or rock which will strike a set of support. The maximum initial speed of nodes of support model was assessed as being equal to $15 \mathrm{~m} / \mathrm{s}$, see McGarr (1997). Another principal applied load was impulse of force (loading impulse) in right part of support, see Fig. 3 and Fig. 5. The time course of loading impulse is identical with course of acting forces, as it is represented in Fig. 6. The total loading impuls I is equal to the value of integral:

$$
\bar{I}=\int_{0}^{\operatorname{tmax}} \bar{F}_{(t)} \cdot d t
$$

The resultant value of impulse is equal approximately to $2 \mathrm{kNs}$. The boundary conditions were selected principally according to Fig. 5. It is a plane set where its left end is clamped and its right end is either a free one (free end) or an articulated shifting one (i.e. simply supported). The profile of support is rolled V-type steel section, i.e both applied sections K24 (weight $24 \mathrm{~kg} / \mathrm{m}$ ) and P28 (weight $28 \mathrm{~kg} / \mathrm{m}$ ). A substitute simplified section which preserves its surface, (moments of inertia of section) and position of centre of gravity are represented in Fig. 7 (Clamp coupling is realized by inserting of one profile into another and by clamping by means of contracting yokes). In this stage of solving the clamp coupling without yield was considered as a rigid and non-functional one.

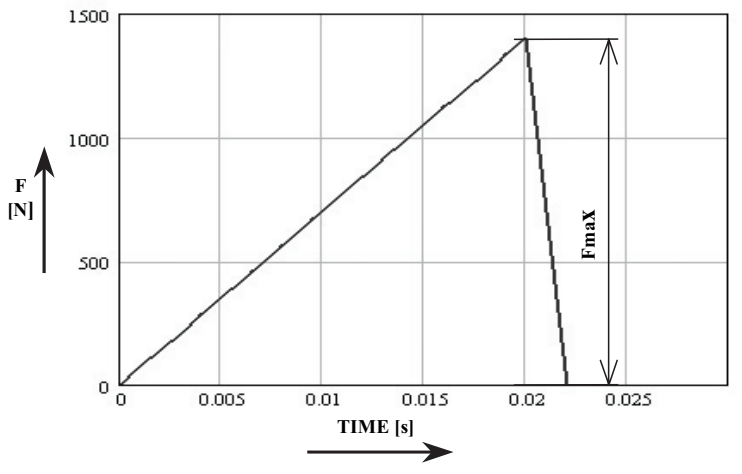

FIG. 6 Course of loading force

\section{RESULTS OF COMPUTATION}

In view of mechanics the solution of dynamic response of support types with plastic properties of material and with large displacements and large strains represents a highly non-linear problem. The stiffness matrix of system is function of displacement. For finite element discretization of roadway support the elementSHELL181 was selected by which all three

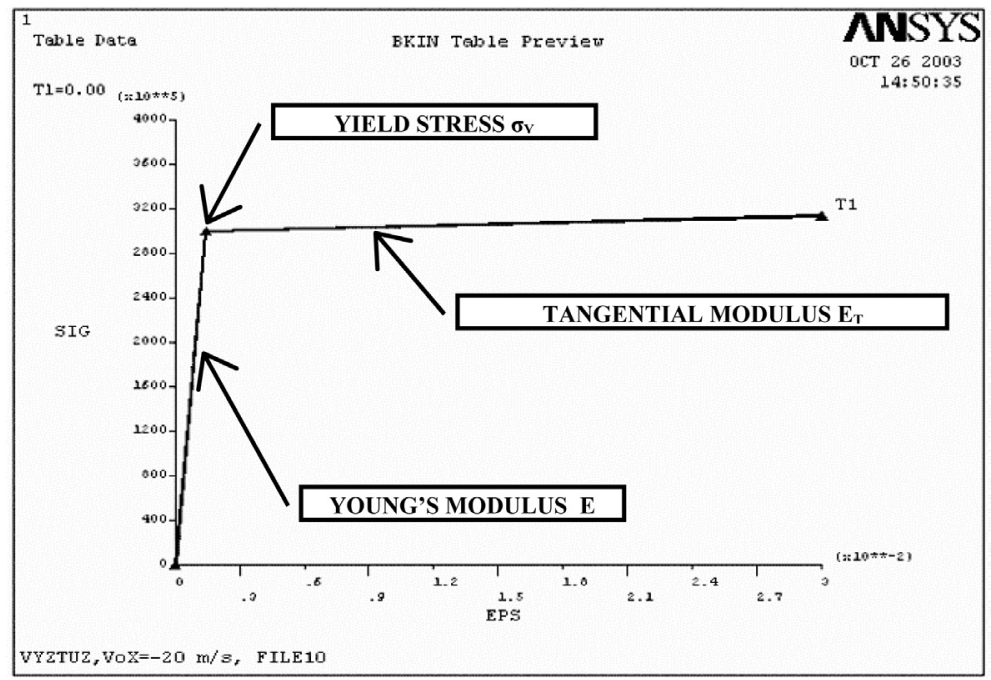

FIG. 4 Bilinear material model

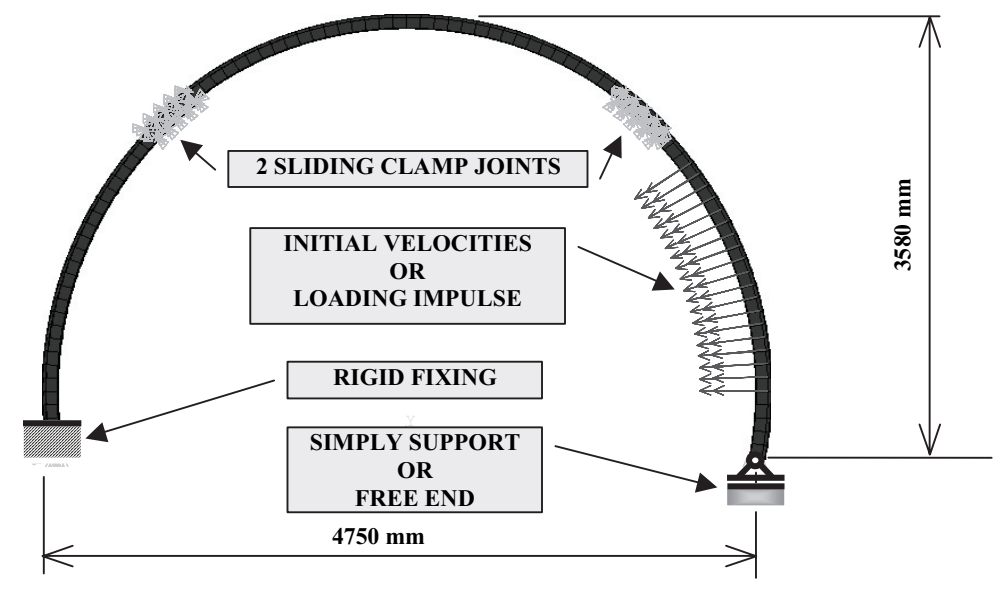




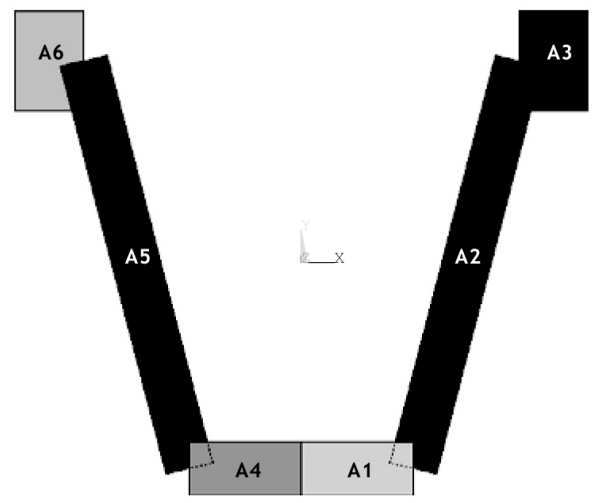

FIG. 7 Substitute shape of profile

types of non-linearity were supported. A linear damping was considered, proportional to stiffness matrix [K]. The matrix of damping $[\mathrm{D}]=\beta \cdot[\mathrm{K}]$ where the coefficient $\beta$ can be determined approximately from relative wind-up $\xi$ of material and the lowest natural freqency $\Omega_{1}$ according to formula $\beta=2 \xi / \Omega_{1}$. The equation of movement (it is differential equation of II. order) is solved numerically by a Newmark implicit "step by step" method. The discretized system represents a problem of order of 10000 degrees of freedom. After termination of action of load the response should be solved as long as the support will lose its kinetic energy and it will remain permanently, i.e. plastically strained. In all types of support the transient response will die away during $0.8 \mathrm{~s}$. The material of support is steel with Young's modulus $\mathrm{E}=210 \mathrm{GPa}$, yield point $\sigma_{\mathrm{y}}=280 \mathrm{MPa}$, tangential modulus of elasticity $\mathrm{E}_{\mathrm{T}}=1176 \mathrm{MPa}$ and ductility of $20 \%$.

\subsection{Roadway Profile 0-00-12, Roadway Support K24}

Basic dimensions of cross-section of roadway of profile 0-00-12 are indicated in Fig. 5. The problem configuration modelled here was a "touchstone" for further advance of solution. In K24 support the influence of packing was not considered. It was unequivocaly verified that by introducing of initial speeds of maximum possible magnitude of $15 \mathrm{~m} / \mathrm{s} \mathrm{no}$ permanent deformation of support was achieved. Maximum deviations of model nodes did not exceed values of $90 \mathrm{~mm}$. Furthermore, it was verified that the boundary condition of free right end is unreal, as it is evident in Fig. 8.

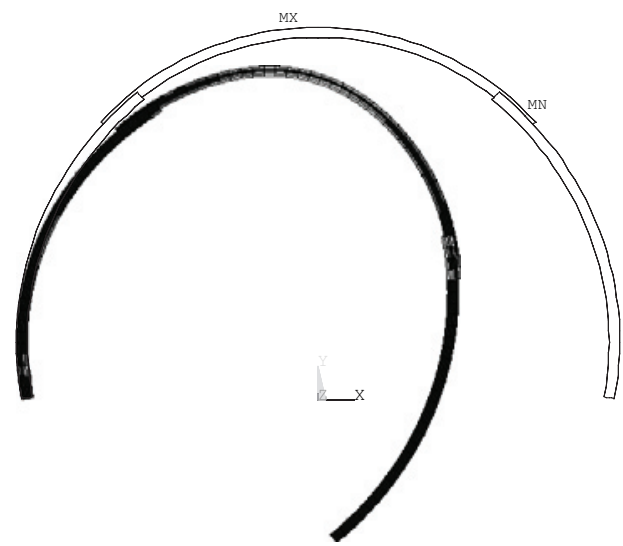

FIG. 8 Plastic deformation for right free end

The right free end is strained in direction towards floor, as if it does not exist. The combination of such boundary conditions therefore was omitted. New parameters of force excitation were determined based on the condition that the right end of support with a simple coupling after dying away of dynamic event would remain permanently deformed at a half of roadway profile, as indicated in Fig. 9. The final values of impulse of force are the following: maximum value of forces is $1400 \mathrm{~N}$, the increase to full value is linear for period of $20 \mathrm{~ms}$ and the drop to null value takes $2 \mathrm{~ms}$ (the course is represented in Fig. 6). For detecting of values of strain and kinetic energy in course of dynamic response a proper subprogram (own macro) was created in programming language APDL of ANSYS program. A typical course of energies during a dynamic process can be seen in Fig. 10 where the final form of plastic strain of roadway support is depicted. The value of this energy is approximately $54 \mathrm{~kJ}$.

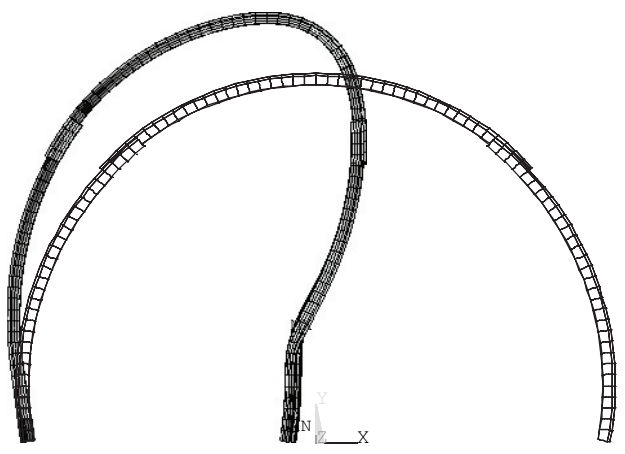

FIG. 9 Final plastic deformation

\subsection{Profiles 0-00-14, 16 and 19, Roadway Support P28}

Similarly as in the preceding part the dynamic response was solved in identical way to three types of roadway profiles as indicated in Fig. 11. The only difference are three clamp couplings, but equally in this case they were modelled as non-functional ones (rigid). The steel support is of section of P28 type having greater weight than that of the abovementioned $\mathrm{K} 24$. The load impulse was again force impulse with identical energy of $2 \mathrm{kNs}$. The time course of energies has the same nature as in the preceding case, see Fig. 12. A little bigger is the value of final accumulated plastic energy, it amounts to about $58 \mathrm{~kJ}$. At a greater value of force of impulse, such as $1700 \mathrm{~N}$ another shape of deformed structure will be achieved, see Fig. 13. At this stage of solution the computer simulations could be more exactly specified by incorporating of influence of surrounding environment. On the one hand incorporation of influence of packing of support in its left part up to level of first clamp coupling and on the other hand a resistance of floor against shift of right end of support was considered. Both such influences were taken into consideration in the model as a form of non-linear springs. Non-linear ones in the sense that they transfer pressure only. They do not act at return movement of roadway support. Also here the damping value was considered as a small one. The value of spring constant of packing was determined from mean value of Young's modulus of elasticity $\mathrm{E}_{\mathrm{obl}}=50 \mathrm{MPa}$. In case of floor a substantially lower modulus value was assumed, i.e. the value $\mathrm{E}_{\text {poč }}=0.5 \mathrm{MPa}$. In ANSYS system such springs were realised by means of elements of LINK10 type with adjustment of their properties so that they transferred only pressure. The required stiffness of spring was achieved by means of numerical combination of cross-section, of its length and of its modulus of elasticity. The final shape of deformed structure was quite different when compared with a support not-affected by such influences, see Fig. 14 . Maximum strain effects were conspicuously less, although the value of accmulated plastic energy was lesser, i.e. $43 \mathrm{~kJ}$, 


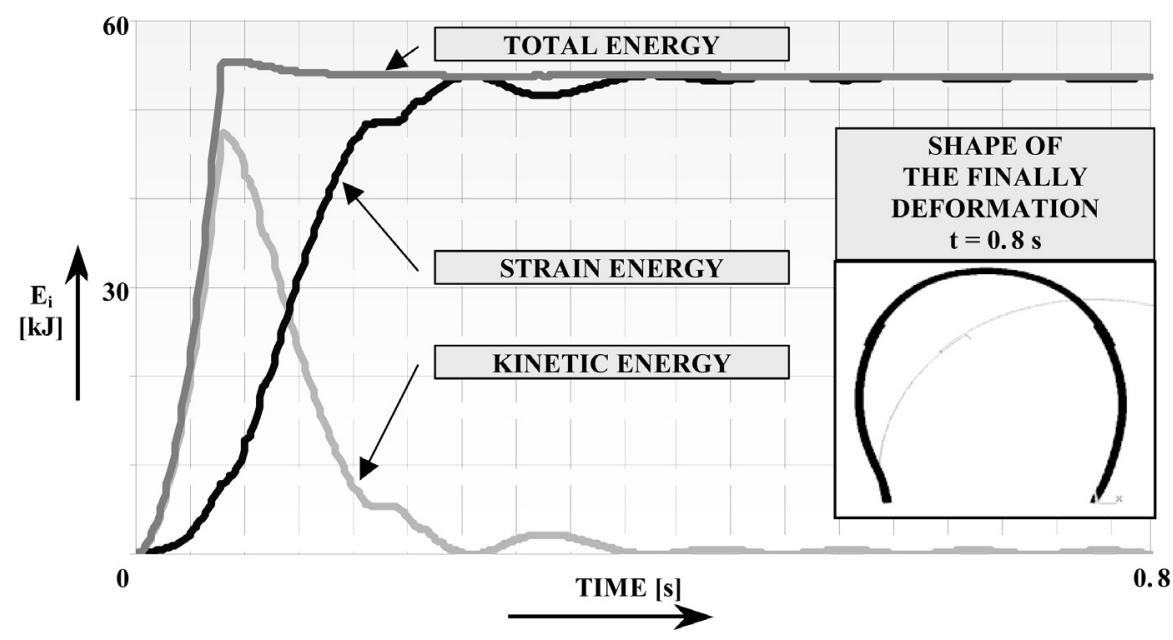

FIG. 10 Course of energies, 0-00-12, K24

when compared with $58 \mathrm{~kJ}$. Decisive factor was busy activity of packing together with roadway floor during the initial period of response between $0-0.2 \mathrm{~s}$. What magnitude of strain energy value is accumulated by the floor and packing during the initial time interval is well evident in course of strain energies as indicated by Fig 15. In its final consequence the plastic energy is distributed more uniformly along structure of roadway support and not so much conspicuous values of permanent strains are achieved. It should be compared the shapes of strained structures in Fig. 10 and Fig. 12 with those in Fig. 14. The results of dynamic simulations in roadway cross-sections 0-00-14 and 0-00-16 are quite analogous. Accumulated plastic strain energy is in the first case $51 \mathrm{~kJ}$ and in the second case $52 \mathrm{~kJ}$. The courses of strain energies are similar (Fig. 15 and Fig. 16).

In case of roadway profile 0-00-19 we meet for the first time with conspicuous "spatial" strain of cross-section profile P28, see Fig. 17. In practice this type of plastic strain occurs in roadways with high degree of roadway support damage.

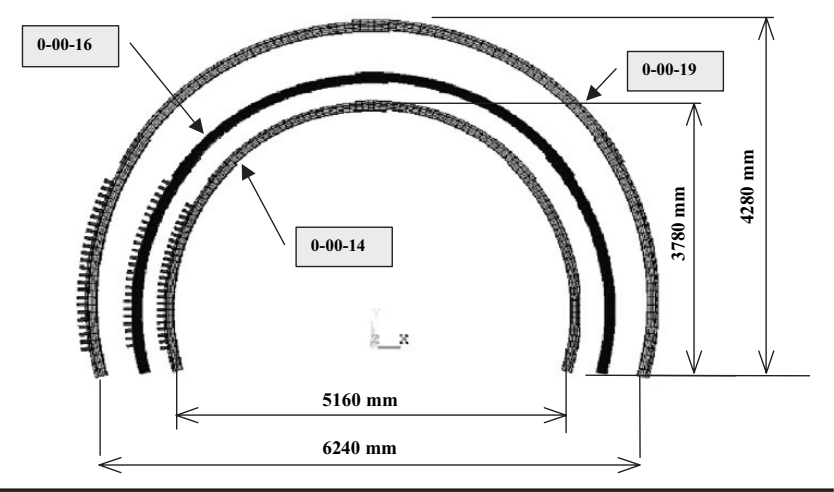

FIG. 11 Size of modelled supports

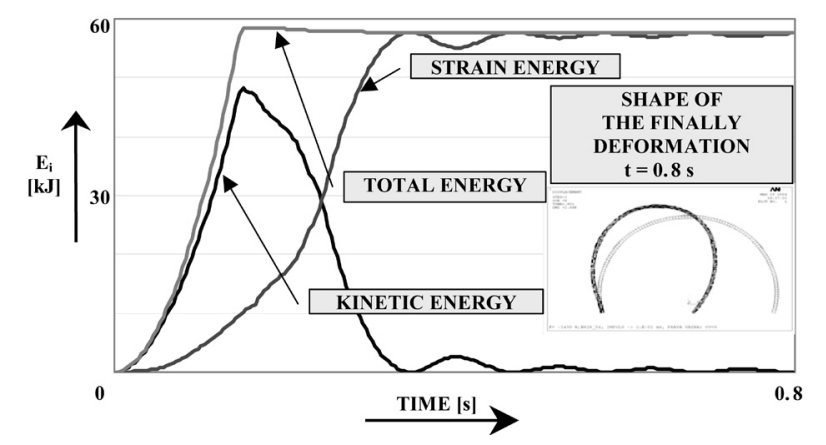

FIG. 12 Course of energies, 0-00-16, P28

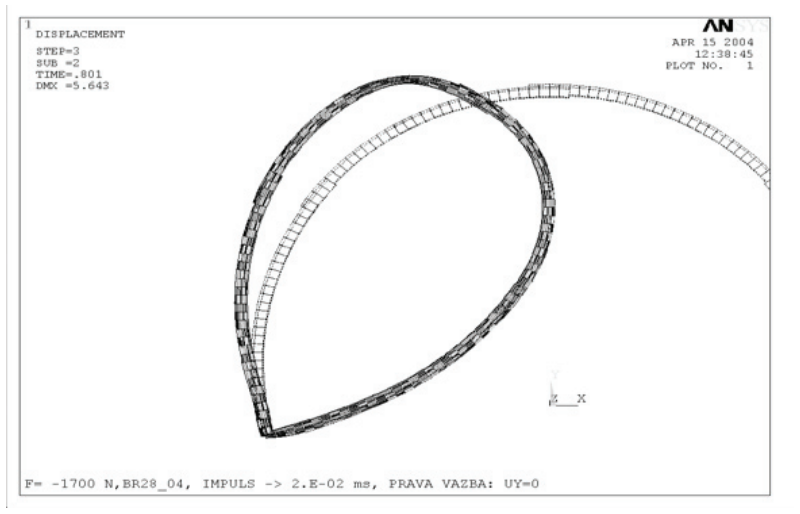

FIG. 13 The shape of final deformation for $F=1700 \mathrm{~N}$, 0-00-16, P28

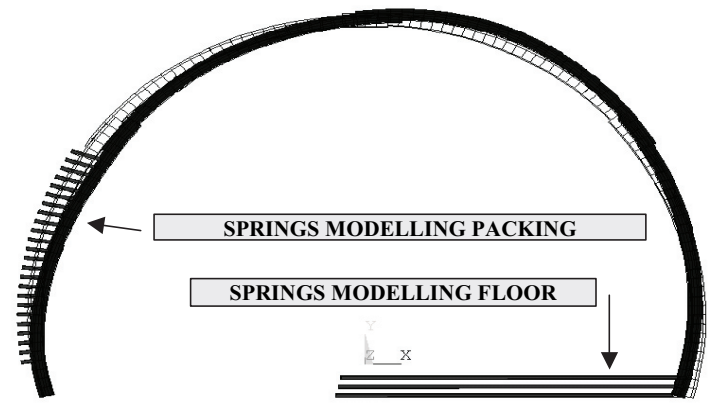

FIG. 14 The shape of final deformation for $F=1400 \mathrm{~N}$, 0-00-16, P28

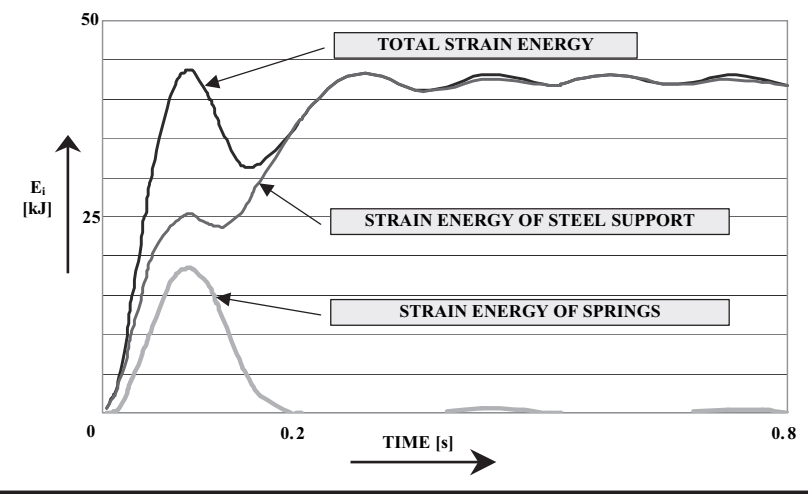

FIG. 15 Course of strain energies with influence of packing and floor, 0-00-16, P28 


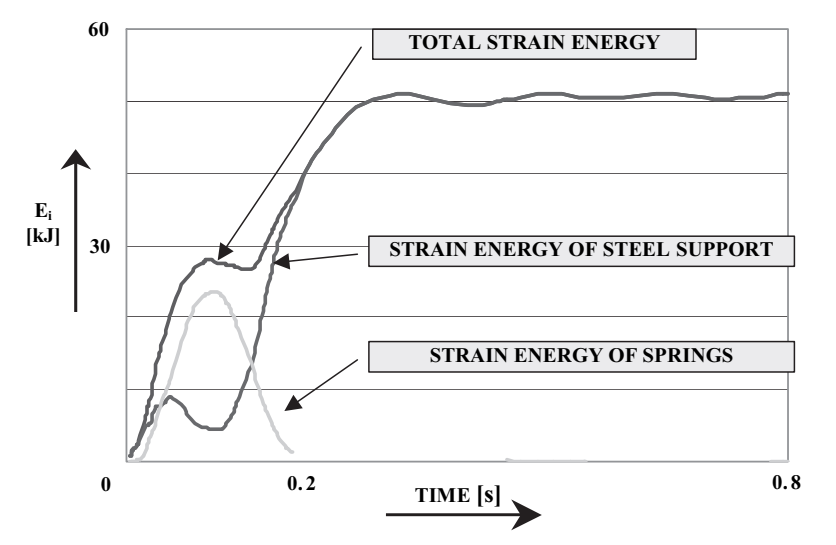

FIG. 16 Course of strain energies with influence of packing and floor, 0-00-14, P28

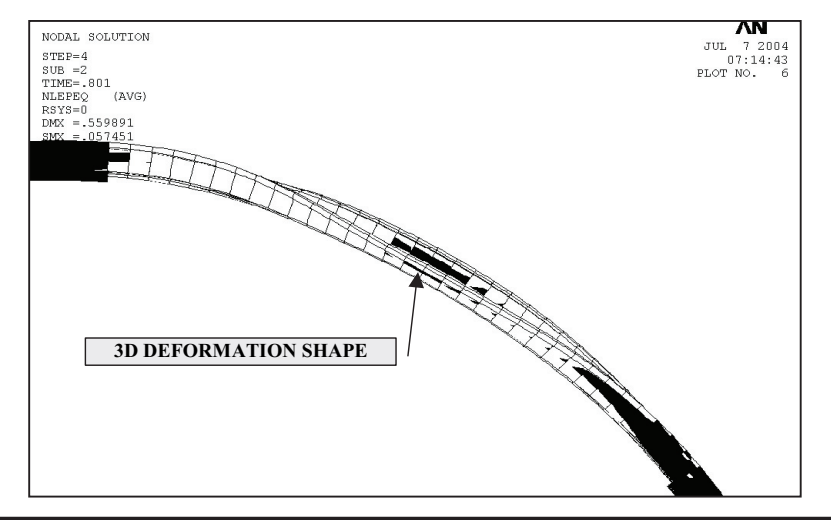

FIG. 17 3D deformation of steel support, 0-00-19, P28

\section{CONCLUSIONS}

Within frame of this stage of solution the basic models of dynamic load of steel arch support of underground roadways being used in areas with rockburst danger were developed.

A verifying was performed of suitable elements for modelling of proper roadway support, of boundary conditions in view of dynamic load of structure during rockburst and of characteristics of ambient environment (resistance of floor against shift of roadway support, characteristics of packing of roadway support). Comparable models were created for three basic applicable sizes of roadway cross-section and for two basic rolled-steel profiles of support segments. From obtained results it ensues that:

- influence of weight of applied rolled steel section of roadway support is manifested less at dynamic load than at static load;

- the values of final accumulated plastic energy in investigated diverse sizes of roadway support are mutually very near;

- packing of roadway support, safeguarding contact with adjacent rockmass, has an essential influence on course and on magnitude of roadway support strain. By packing of roadway support a considerable share of strain energy is accumulated during initial time interval which leads at the same time to reducing of permanent strain of roadway support.

In further stages of solution based on mathematical modelling we will investigate variants of potential measures of improvement of roadway resistance and of roadway support (closed support, anchoring elements, change of strength and deformation properties of adjacent rockmass).

\section{ACKNOWLEDGMENT}

The work was elaborated within frame of the project No 34/2003 of Research and Development Programme of Czech Mining Authority and of government grant project No GAČR 101/04/1145.

\section{REFERENCES}

Horyl, P. and Hlaváčková, M. (1999) The Buckling Analysis of Steel Truss Support in Shotcrete in Tunnelling. In 17. CAD-FEM USERS' MEETING, Grafing bei München: CAD-FEM GmbH, ref. I.3.9, pp. 1-15.

Konečný, P., Velička, V., Šňupárek, R., Takla, G. and Ptáček, J. (2003) Rockbursts in period of mining activity reduction in Ostrava-Karviná Coalfield. In Proceedings of 10th ISRM congress 2003, Sandton, Vol.1, pp. 665-668.

McGarr, A. (1997) A Mechanism of High Wallrock Velocities in Rockbursts. Pure Application Geophysics 150, pp. 381-391. 